\title{
Sabina Baraniewicz
}

Uniwersytet Opolski

\section{FENOMEN WIODĄCEJ POZYCJI GOOGLE W BRANŻY WYSZUKIWANIA W UJEZCIU HISTORYCZNYM. POŚREDNIE CZYNNIKI SUKCESU}

\author{
Abstract \\ THE PHENOMENON OF THE GOOGLE'S LEADING POSITION \\ ON THE SEARCH MARKET IN A HISTORICAL APPROACH. \\ INDIRECT SUCCESS FACTORS
}

Google, once a student project, now a real empire of the ICT (Information and Communication Technologies) industry. Its power Google has built on the commercialization of information and the access to it. Its trailblazing project - the search engine, has ensured it nearly monopolistic position on the search market. Google its success on this marketplace does not owe only to the creation of the very useful and functional information search tool; the influence on it has had many more indirect factors, which has foredoomed the fiasco of other offering the same product competitory corporations.

Key words: Google, information, search engine, Internet, indirect success factors

\section{Wstęp}

Wyszukiwarka jako narzędzie samo w sobie nie jest wynalazkiem Google; jednak to produkt właśnie tej firmy stworzony przez dwudziestokilkuletnich doktorantów, Larry’ego Page’a i Sergeya Brina, zrewolucjonizował pojęcie wyszukiwania informacji w sieci - z wyszukiwarki Google Search korzysta obecnie ponad 90\% internautów w Europie ${ }^{1}$. Tym, zdawałoby się, nic niewiedzącym o zarządzaniu

${ }^{1}$ Ochrona konkurencji: Komisja kieruje do Google pisemne zgłoszenie zastrzeżeń w zwiąku zsystemem operacyjnym Android i aplikacjami mobilnymi, www.europa.eu/rapid/press-release (dostęp: 18.06.2016). 
studentom kierunków informatycznych i matematycznych, którzy szalony jak na owe czasy projekt rozwijali w swoich pokojach akademickich, udało się ulepszyć istniejące rozwiązania ówczesnych korporacji w branży wyszukiwania informacji, a także wykreować zupełnie nowe. Pomimo niewielkiej, choć istniejącej konkurencji, to właśnie Google zdołał najefektywniej uporządkować światowy zasób informacji w sieci oraz stworzyć niezwykle dochodowy model biznesowy firmy, którego podstawę - można by rzec - nie stanowi nic innowacyjnego, a jedynie reklama i marketing. Model ten nierzadko decyduje dziś o sukcesie wielu innych firm; pozwala na ich szybkie odnalezienie w chaosie sieciowych danych, jak również na dotarcie do potencjalnych klientów, a także znalezienie się w wynikach wyszukiwania i zaprezentowanie swoich produktów i usług przed konkurencją.

Google swojego sukcesu na rynku wyszukiwania nie zawdzięcza jednak tylko stworzeniu zaawansowanego technologicznie i bardzo funkcjonalnego narzędzia do szukania informacji - to narzędzie poniekąd już istniało, choć faktycznie algorytm napisany przez twórców Google okazał się najatrakcyjniejszy. Na jego sukces w branży wpłynęło również wiele czynników jeszcze z czasów kształtowania się narzędzi do wyszukiwania informacji w sieci, które - często niedostrzegane - pośrednio także przysłużyły się wyszukiwarce Google i przesądziły o fiasku innych firm, oferujących te same usługi, lecz nie tak popularnych jak omawiana korporacja. O niektórych elementach, które mogą wpłynąć na przyjęcie się danej technologii czy rozwiązania, wspominał w swojej książce Strzelby, zarazki, maszyny. Losy ludzkich społeczeństw Jared Diamond: to poniekąd tak niezależne od poczynań firm kwestie, jak rozwój nowszych, usprawniających daną technikę technologii, swoiste społeczne zmiany w sposobie ich postrzegania czy pojawienie się innych innowacji, dzięki którym te już istniejące mogą dopiero zacząć odpowiednio funkcjonować2. Aby wskazać te zależności powstałe głównie na skutek czasu, ale także uwarunkowane miejscem rozwijania projektu młodych doktorantów, posłużono się przytoczeniem historii wyszukiwarek oraz samej firmy Google. Dla podkreślenia czynników, które zadziałały na korzyść rozwoju jednej z największych współczesnych korporacji, przywołano jednak tylko elementy najważniejsze z punktu widzenia analizy niniejszej pracy. $Z$ tego też powodu analiza ta nie zawsze będzie przebiegać chronologicznie, częściej zaś problemowo.

\section{Fiasko wyszukiwarek przed Google}

Miano pierwszej internetowej wyszukiwarki przyznaje się Archie. Program ten stworzyli w 1990 roku dwaj studenci oraz pracownik kanadyjskiego Uniwersytetu McGilla jeszcze przed powstaniem sieci WWW. W owych czasach Internet służył

2 J. Diamond, Strzelby, zarazki, maszyny. Losy ludzkich społeczeństw, Prószyński i S-ka, Warszawa 2000, s. 280-281. 
naukowcom głównie do kolekcjonowania różnych dokumentów i prac naukowych dostępnych na publicznych komputerach. Jako że tych ciągle przybywało, program Archie miał pomóc w ich przeszukiwaniach - po wpisaniu w aplikację słów kluczy powiązanych z nazwą szukanego pliku Archie wskazywał komputer, na którym był umieszczony dany dokument. Stworzony trzy lata później program Veronica nie tyle pokazywał urządzenie, na którym znajdował się poszukiwany plik, ile bezpośrednio już się z nim łączył ${ }^{3}$. Nadal jednak wyszukiwanie opierało się jedynie na tytułach artykułów. Rozwiązanie to, choć wciąż niedoskonałe, na pewno było lepsze niż żmudne przeczesywanie zawartości każdego komputera samodzielnie.

Wraz z nadejściem ery WWW Archie i Veronica zaczęły tracić na swojej funkcjonalności; sieć rozrastała się w błyskawicznym tempie i comiesięczne aktualizacje baz danych jak również serwery je przechowujące przestały być wystarczające. Należało więc dostosować model wyszukiwania do szybko zmieniających się warunków. Na tę potrzebę zaczęły odpowiadać pojawiające się powoli kolejne wyszukiwarki. Istotną rolę $\mathrm{w}$ ich ewolucji odegrał program WebCrawler, który jako pierwszy zaoferował możliwość pełnotekstowego wyszukiwania dokumentów znajdujących się w Internecie ${ }^{4}$. Ta funkcja okazała się niezwykle przydatna nie tylko naukowcom - rozwiązanie to zaczęło znacznie upraszczać sposób korzystania z sieci także zwykłym konsumentom.

Znaczący wpływ na współczesny model wyszukiwania treści w sieci miała opracowana w 1995 roku wyszukiwarka AltaVista. Jej twórca, badacz Louis Monier, był związany z amerykańską firmą informatyczną Digital Equipment Corporation (DEC), która w tym okresie borykała się z problemami finansowymi i dlatego też szukała oryginalnego sposobu na promocję swojego nowego sprzętu, dopiero co wypuszczonego na rynek. Był to komputer Alpha, w którego firma wbudowała znacznie szybszy i mocniejszy procesor od dotychczas istniejących. Monier zaproponował więc załadowanie na niego „wielkiej bazy danych Internetu” - chodziło po prostu o przeniesienie informacji $\mathrm{z} \mathrm{w}$ miarę stabilnej ówcześnie pojemnościowo sieci na jeden dysk ich pionierskiego urządzenia z możliwością przeszukiwania jej zawartości. Dla DEC miała to być jedynie demonstracja sprzętu, ale dla Moniera produkt ten stanowił odpowiedź na problem związany $\mathrm{z}$ wyszukiwaniem treści w Internecie. Mimo że w tym czasie istniało już kilkanaście wyszukiwarek, żadna nie była wystarczająco funkcjonalna i nie prezentowała odpowiednio zasobów Internetu ${ }^{5}$.

Firma, w której pracował Monier, do końca nie rozumiała, dlaczego miałaby promować na rynku wyszukiwarkę, skoro zajmowała się produkcją urządzeń. Jej twórca w końcu zdołał namówić dyrekcję do publicznego udostępnienia witryny,

${ }^{3}$ J. Battelle, Szukaj. Jak Google i konkurencja wywołali biznesowa i kulturowa rewolucje, Wydawnictwo Naukowe PWN, Warszawa 2006, s. 34.

4 Tamże, s. 36.

5 Tamże, s. 36-39. 
która zindeksowała już wtedy ponad 16 milionów stron i miliardy słów ${ }^{6}$. Bez oficjalnych zapowiedzi i reklamy tylko pierwszego dnia AltaVista przyciągnęla prawie 300 tysięcy osób, a w ciągu roku obsłużyła ponad 4 miliardy zapytań. Brak umiejętności spółki w zarządzaniu wyszukiwarką i radzeniu sobie z jej rosnącą popularnością przekreślił jednak sukces dobrze zapowiadającego się biznesu?

Choć Monier dostrzegał potrzeby użytkowników sieci i zdawał sobie sprawę z użyteczności wyszukiwarki w przestrzeni Internetu, nie udało mu się przekonać spółki do funkcjonalności i fenomenu jego produktu. Także firma, która później przejęła DEC, nie rozumiała narzędzia, jakim jest platforma do wyszukiwania treści w sieci. Dziś stanowi ona podstawę w poruszaniu się po jej zasobach i odnajdywaniu szukanych stron internetowych oraz materiałów. Wtedy, pomimo oszczędności czasu, jaką wyszukiwarka gwarantowała, nie przywiązywano do niej większej wagi z prostej przyczyny - nie dostrzegano jej biznesowego zastosowania, dlatego nie inwestowano zbytnio w rozwój wyszukiwania treści. Z tego też powodu AltaVistę przekształcono na wzór Yahoo! w portal z pocztą elektroniczną, katalogami, grupami dyskusyjnymi i migającymi reklamami w tle, na których firma mogła już zarabiać.

Jako że sieć WWW była jeszcze młodą technologią, wielu nie zdawało sobie sprawy z jej szybko powiększających się rozmiarów, a tym samym z potrzeby działania uporządkowanego katalogu, który potrafiłby posegregować pojawiające się coraz większe ilości treści. Obecnie kluczowe dla odnalezienia się w chaosie zasobów Internetu jest wyszukiwanie informacji właśnie poprzez dobrze zorganizowany i opisany indeks stron internetowych. Nie dostrzegając w latach 90. tej zależności, traktowano wyszukiwarki jedynie jako drugorzędne narzędzie, a nie niezbędny element rozwoju Internetu. Takie rozumowanie pokazuje, że na tym etapie rozwoju sieci wciąż jeszcze nie pojmowano zjawiska, jakim był Internet. To swoiste, wciąż jeszcze kształtujące się novum wielu przedsiębiorców za bardzo pojmowało w starych kategoriach ekonomicznych, które w obliczu nowego medium nie miały zastosowania. Brakowało im wizjonerskiego podejścia, dzięki któremu potrafiliby zaadaptować nowoczesne technologie do wykreowania zupełnie nowych trendów możliwych jedynie dzięki Internetowi. Inaczej sytuacja przedstawiała się w środowisku akademickim, które brało udział w tworzeniu sieci niemal od początków jej istnienia, a w którym też rozwijał się googleowski projekt. Tu naukowcy, a jak się potem okazało - przede wszystkim studenci, znacznie lepiej rozumieli złożoność Internetu i potrafili dostrzec możliwości, jakie ze sobą niesie. W komercyjnym środowisku pracy związanym z produkcją minikomputerów i procesorów Monier nie znalazł osób, które rozumiałyby te kwestie tak dobrze jak on. Choć był to dobry czas na powstanie wyszukiwarek (na co wskazywały liczby użytkowników

${ }^{6}$ Ch. Sherman, Search Engine Birthdays, www.searchenginewatch.com (dostęp: 22.06.2016).

7 J. Battelle, dz. cyt., s. 40, 43.

${ }^{8}$ A. Suárez Sánchez-Ocaña, Tajemnice Google’a. Wielki Brat ery informatycznej, Bellona, Warszawa 2013, s. 17. 
AltaVisty), ze względu na brak odpowiedniego modelu biznesowego, bez którego komercyjne firmy nie chciały nawet podjąć się rozwoju sieciowych katalogów, nie dostrzegano ich użyteczności. To w przyszłości przesądziło też o sukcesie na tym polu rozwijanego początkowo w warunkach niekomercyjnych Google.

W 2004 roku AltaVista ostatecznie trafiła w ręce Yahoo!, które przywróciło jej pierwotny wygląd, jednak w obliczu popularności, jaką wtedy cieszyła się już wyszukiwarka Google Search, zupełnie straciła na znaczeniu9. Teoretycznie, gdyby wcześniejszy sztab zarządzający aplikacją dostrzegł potencjał AltaVisty, mogłaby ona po części stać się takim Google. Była to pierwsza wielojęzyczna wyszukiwarka, która obsługiwała także niełaciński alfabet i oferowała narzędzie do tłumaczenia stron. Wprowadziła również tak innowacyjne rozwiązania jak możliwość wyszukiwania za pomocą całych fraz tekstowych czy wyszukiwanie samych multimediów (obrazów i wideo ${ }^{10}$. Przed powstaniem Google obok portali Yahoo! i AOL wyszukiwarka AltaVista była jednym z najważniejszych miejsc w sieci ${ }^{11}$.

Historia pokazuje, że największą wadą programu Moniera było jego zbyt szybkie pojawianie się na rynku - w czasach, gdy jeszcze nie udało się przekonać przedsiębiorstw do użyteczności i opłacalności wyszukiwarek, choć przecież statystyki pokazywały, że cieszą się one ogromnym zainteresowaniem wśród użytkowników sieci. Problem stanowiło to, że owa użyteczność była pojmowana przez firmy rynku kapitalistycznego jedynie w kategoriach ekonomicznych - skoro nie potrafili wymyślić sposobu na zarabianie na wyszukiwarkach, nie widzieli sensu w ich utrzymywaniu, nawet jeśli narzędzie to było samo w sobie bardzo funkcjonalne. „Nikt nie wiedział, jak zarabiać pieniądze na wyszukiwaniu. Były one postrzegane jako przekaźnik ruchu na inne, bardziej dochodowe biznesy, kiedy to w rzeczywistości wyszukiwarka była biznesem. To nie było takie oczywiste w tamtym czasie" - tłumaczył się Joe Kraus, współtwórca innej dobrze zapowiadającej się wyszukiwarki, Excite, który podobnie jak inni z branży nie potrafil przeobrazić swojego progra$\mathrm{mu} \mathrm{w}$ dochodowy interes ${ }^{12}$.

Przedsiębiorcy nie umieli więc odnaleźć komercyjnego zastosowania wyszukiwarki, którą użytkownicy sieci włączaliby tylko na chwilę po to, by po znalezieniu tego, czego szukają, zaraz opuścić jej okno i udać się na inną stronę. Obawiali się, że po kilku takich wyszukiwaniach internauci odnaleźliby wszystkie interesujące ich strony, zapisali je i wtedy już nie potrzebowaliby więcej używać wyszukiwarek. Z perspektywy czasu, wiedząc, jak dziś wygląda wyszukiwanie informacji online, obawa ta wydaje się dla nas zupełnie niezrozumiała. Wówczas jednak, jak już wspomniano, sieć nie była jeszcze tak rozbudowana jak obecnie. Nie zdawano

9 J. Battelle, dz. cyt., s. 40, 43.

10 Zob. www.web.archive.org/web/19961022174810/http://www.altavista.com/ (dostęp: 10.05.2016). Strona archiwalna pokazująca wygląd i rozwój wyszukiwarki AltaVista przez lata funkcjonowania.

${ }^{11}$ J. Battelle, dz. cyt., s. 42.

12 J. Livingston, Founders at Work: Stories of Startups' Early Days, Apress, New York 2008, s. 68. 
sobie także sprawy z jej szybko powiększających się rozmiarów, stąd obawy przed inwestycją w niedochodowe projekty w pewnym aspekcie mogą tłumaczyć odrzucanie pomysłów związanych $\mathrm{z}$ wyszukiwaniem informacji w sieci. To między innymi te kwestie przesądziły o porażce podjętych projektów w branży wyszukiwania i pozwoliły na swobodny rozwój, a następnie przebicie konkurencji i szybką popularność Google.

\section{Sukces Google na rynku wyszukiwania}

Larry Page i Sergey Brin, dwudziestokilkuletni studenci Uniwersytetu Stanforda, początkowo nie rozpatrywali swojego projektu w kategoriach stricte ekonomicznych. Powstawał on w 1996 roku jako konieczny element bardzo ambitnej pracy doktorskiej, który okazał się niezwykle funkcjonalny i nowatorski. Młodzi badacze zafascynowani komputerami i siecią WWW chcieli stworzyć wyszukiwarkę, która w przeciwieństwie do tych istniejących potrafiłaby dodatkowo porządkować i klasyfikować wyniki wyszukiwania na podstawie ich relewancji, a więc pod kątem logicznej zgodności odpowiedzi z postawionym zapytaniem - większość wyszukiwarek wyświetlała po prostu linki zawierające szukaną frazę. W tym celu Page i Brin opracowali oparty na matematycznych formułach algorytm, który porządkował strony internetowe na podstawie oceny ważności ich wzajemnych powiązań $\mathrm{w}$ sieci ${ }^{13}$. Rozwiązanie to zaczerpnęli $\mathrm{z}$ dobrze znanej im akademickiej metody oceny artykułów naukowych, która określała jakość tekstu proporcjonalnie do liczby artykułów na niego się powołujących. Przekładając to na indeks wyszukiwarki Google: jej twórcy oszacowali, że strona internetowa, na którą powołuje się inna popularna strona, będzie bardziej wartościowa, niż gdyby na tę samą stronę powoływał się tekst $\mathrm{z}$ tej mniej znanej, a więc mniej wartościowy ${ }^{14}$. Algorytm w ten sposób indeksujący zawartość Internetu nazwano na cześć jednego z twórców Google PageRank. Dziś to najbardziej znana metoda szeregowania stron internetowych w wynikach wyszukiwania.

Studencki projekt został najpierw udostępniony w obrębie Uniwersytetu Stanforda. Indeks stron, w którym odnośniki (tzw. linki) pełniły analogiczną funkcję jak cytowane dzieła w pracach naukowych, doskonale przyjął się w akademickim środowisku ${ }^{15}$. Profesorowie i studenci uczelni po jakimś czasie przestali używać innych dostępnych wyszukiwarek - Google był znacznie skuteczniejszy i do tego podawał wyniki wyszukiwania $\mathrm{w}$ czasie krótszym niż jedna sekunda ${ }^{16}$. Popularniejsze strony, do których prowadziło najwięcej linków, trafiały na wyższe pozycje

\footnotetext{
13 A. Suárez Sánchez-Ocaña, dz. cyt., s. 18.

${ }^{14}$ Ippolita, The Dark Side of Google, Institute of Network Cultures, Amsterdam 2013, s. 27.

15 J. Battelle, dz. cyt., s. 62.

16 A. Suárez Sánchez-Ocaña, dz. cyt., s. 19.
} 
w rankingu wyszukiwania, a mniej popularne - na niższe. Page i Brin przeobrazili Internet w skomplikowane matematyczne równania, których zasady obliczeniowe wymagane do analizy powiększającej się w tempie $2000 \%$ rocznie sieci WWW przekraczały już przyjęte granice studenckich projektów ${ }^{17}$. W 1998 roku ich katalog obejmował 26 milionów stron. W ciągu sekundy potrafił przeanalizować tekst $\mathrm{z}$ około tysiąca stron, następnie wychwycić wszelkie powiązania z innymi odnośnikami i zapisać je w bazie danych ${ }^{18}$.

Szybkość, z jaką twórcy wyszukiwarki Google pozwalali użytkownikom sieci odnajdywać informacje, w głównej mierze była wynikiem konstrukcji ich strony. Doktoranci postawili na zupełny minimalizm: pośrodku białej strony umieścili jedynie logo Google wypełnione podstawowymi kolorami oraz okno wyszukiwania. Był to ogromny kontrast w porównaniu do stron ówczesnych liderów na rynku wyszukiwania. AltaVista na wzór Yahoo! przepełniona była kolorowymi, krzykliwymi banerami reklamowymi; podobnie przedstawiał się Lycos (wyszukiwarka, która również w tamtym czasie działała na rynku i także odegrała znaczącą rolę w historii wyszukiwań $)^{19}$. Nie będąc przeciążona zawartością, bez nadmiaru zbędnych grafik i reklam, wyszukiwarka Google przyciągała uwagę swoją skromną stroną startową. Studenci realizujący ten projekt $w$ ramach pracy naukowej mogli sobie jednak pozwolić na tego typu prezentację - jako że nie było to przedsięwzięcie komercyjne, nie musieli martwić się o sprzedaż miejsc reklamowych. Dzięki temu mogli skupić się na realnych potrzebach użytkowników związanych z wyszukiwaniem. Konkurencja większą wagę przywiązywała do gromadzenie jak największej liczby internautów i wydłużanie czasu spędzanego na ich stronach internetowych, aby podnieść poziom konsumpcji swoich reklam.

Jako że ówczesną branżą wyszukiwania zajmowały się największe internetowe przedsiębiorstwa, w 1998 roku Page i Brin postanowili sprzedać im licencję na swój produkt za milion dolarów i nie konkurować z nimi ${ }^{20}$. Pojawiały się głosy, że jak na projekt, który nie przyniósł jeszcze żadnych dochodów, była to zbyt wysoka cena. Zarówno AltaVista, dla której połączenie swojej wyszukiwarki z Google gwarantowałoby dostęp do największej bazy danych adresów stron internetowych, jak i Yahoo!, które nie miało własnej wyszukiwarki, odrzucili ofertę. Projekt im się podobał, ale nie byli zainteresowani jego zakupem. Yahoo! nie chciało, aby wyszukiwarka „wyprowadzała” internatów z ich portalu, a tym samym oddalała ich od reklam na ich witrynie ${ }^{21}$. Wiedząc dziś, czym obecnie jest Google, pewnie wiele firm, które odrzuciły wtedy ofertę, żałuje, że nie rozpatrzyły lepiej propozycji studentów.

${ }_{17}$ J. Battelle, dz. cyt., s. 59.

18 A. Suárez Sánchez-Ocaña, dz. cyt., s. 15, 28.

${ }^{19}$ L. Reppesgaard, Imperium Google. Google zna Cię lepiej, niż sądzisz..., BC.edu, Warszawa 2009, s. 12.

${ }^{20}$ A. Suárez Sánchez-Ocaña, dz. cyt., s. 20. Według innych źródeł Page ustalił cenę Google na 1,6 mln dolarów.

${ }^{21}$ Tamże, s. 21. 
Nie jesteśmy jednak w stanie stwierdzić, czy potrafiłyby one przeobrazić wyszukiwarkę w tak dochodowy interes jak jej twórcy.

Pod koniec 1998 roku Google obsługiwał dziennie ponad 10 tysięcy zapytań, a jego serwery były już u kresu wytrzymałości ${ }^{22}$. Jako że doktorantom nie udało się sprzedać swojego produktu, nie pozostało im nic innego jak tylko założyć własną działalność i pozyskać na nią zewnętrzne fundusze. Ta porażka w próbie sprzedaży swojego pomysłu przerodziła się w ich największy życiowy sukces, który zagwarantował im dziś bycie jednymi z najbogatszych ludzi świata.

7 września 1998 roku firma Google Inc. oficjalnie rozpoczęła swoją działalność z biurem i „centrum programowania” $\mathrm{w}$ garażu wynajmowanym od znajomej. Finansowym wsparciem powstającego biznesu zainteresował się Andy von Bechtolsheim, ekspert komputerowy i współzałożyciel Sun Microsystems ${ }^{23}$. Kilka miesięcy później w start-up młodych doktorantów zainwestowały również dobrze znane w Dolinie Krzemowej firmy inwestorskie, które wyceniły spółkę na około 125 milionów dolarów. Sequoia Capital oraz Kleiner Perkins Caufield \& Byers inwestowały wcześniej już w AOL, Yahoo! czy Excite. Oddanie jednak tak dużej kwoty młodym biznesmenom bez doświadczenia w zarządzaniu było sporym ryzykiem, dlatego inwestorzy zdecydowali się przekazać swoje pieniądze pod warunkiem zatrudnienia dyrektora generalnego $\mathrm{z}$ doświadczeniem $\mathrm{w}$ branży ${ }^{24}$. Umowa Google z prestiżowymi finansistami pomogła mu rozwinąć swój biznes, a także wobec rozgłosu spowodowanego tym faktem zaistnieć w Dolinie.

Po wsparciu finansowym uniwersytecki projekt rozwijał się w oszałamiającym tempie. AOL i Netscape wybrały produkt zaledwie rocznej firmy na swoją wyszukiwarkę; w ten sposób Google dorobiło się 3 milionów wyszukiwań dziennie, a pod koniec 1999 roku - 7 milionów. W roku 2000 średnia liczba dziennych użytkowników wynosiła 15 milionów; tempo odwiedzin nieustannie rosło. Również Yahoo! zdecydowało się uczynić Google dostawcą wyszukiwań dla swoich użytkowników. To zwiększyło prestiż firmy z Mountain View, ale dla Yahoo! oznaczało powolną kapitulację w obliczu wzrastającej potęgi nowej firmy, której kupno wyszukiwarki kiedyś odrzuciło ${ }^{25}$.

W 2000 roku Google udało się poszerzyć model biznesowy swojej wyszukiwarki o aukcyjną sprzedaż słów kluczy, za pomocą których ludzie wyszukiwali treści w Internecie - w ten sposób firma zaczęła osiągać ogromne zyski. To właśnie brak tego modelu przesądzał o fiasku wcześniejszych projektów związanych z wyszukiwaniem

${ }^{22}$ Ippolita, dz. cyt., s. 27.

23 Tamże.

${ }^{24}$ R.L. Brandt, Potęga Google’a: poznaj sekrety Larry’ego i Sergeya, Znak, Kraków 2011, s. 57. Page i Brin długo zwlekali z zatrudnieniem nowego dyrektora. W końcu stanowisko to w 2001 roku objął Eric Schmidt. Były prezes Novell, firmy specjalizującej się w sieciowych systemach operacyjnych, okazał się doświadczonym biznesmanem rozumiejącym potrzeby związane $\mathrm{z}$ wyszukiwaniem informacji w sieci. Wraz z młodymi twórcami Google stworzył doskonały zespół zarządzający spółką.

${ }_{25}$ A. Suárez Sánchez-Ocaña, dz. cyt., s. 31, 33-34. 
treści. Kolejny system polegający na płaceniu za realne kliknięcie w reklamowany link, a nie jedynie za jego zobaczenie, okazał się w przypadku Google równie skuteczny - ogłoszeniodawcy w końcu mogli uzyskać mierzalne wyniki swoich kampanii reklamowych. Model ten nie został jednak w pełni stworzony przez Google - wymyślił go w 1998 roku Bill Gross, twórca wyszukiwarki GoTo.com. Mimo że tak zwany model pay-per-click (płać za kliknięcie) przynosił GoTo.com duże zyski, ludzie, z którymi współpracował Gross (podobnie jak w przypadku Moniera), nie wierzyli do końca w sukces biznesowy jego wyszukiwarki i swoimi decyzjami doprowadzili do jej upadku. Google zaadaptował więc w 2002 roku nieopatentowany model Grossa do swoich usług, a jego twórcy nie pozostało nic innego jak dochodzić swych praw w sądzie ${ }^{26}$ i patrzeć, jak Google rośnie w siłę za sprawą wymyślonego przez niego sposobu zarabiania na wynikach wyszukiwania, stając się niemal monopolistą w branży związanej z wyszukiwaniem informacji w sieci.

\section{Podsumowanie}

W istocie Google dziś to nie tylko wyszukiwarka Google Search, ale też ogromne imperium internetowe, które bacznie obserwuje społeczne trendy i szybko adaptuje się do otaczającej go rzeczywistości. Przy wielu sprzyjających czynnikach, z których część starano się wykazać w niniejszym artykule, a także dzięki innowacyjnemu spojrzeniu twórców Google na nowe technologie, rozumieniu specyfiki sieci i potrzeb jej użytkowników, a w końcu bardzo dobremu zarządzaniu firmą to właśnie im udało się uporządkować światowy zasób informacji w Internecie i skomercjalizować ludzką potrzebę wyszukiwania informacji oraz stworzyć najlepsze narzędzie, bez którego dziś właściwie nie jesteśmy w stanie poruszać się po zasobach sieci.

Prócz wyszukiwarki Google oferuje wiele innych usług i narzędzi, także tych niezwiązanych z pierwotną linią firmy opartej na wyszukiwaniu informacji, a umożliwiających również jej przechowywanie, udostępnianie czy analizę i personalizację. To m.in. elektroniczna poczta Gmail, przeglądarka Chrome, sieciowy dysk Google Drive, portal społecznościowy Google+, platforma wideo YouTube, serwis z książkami Book Search, wyszukiwarka materiałów edukacyjnych i wyników badań Google Scholar, Google Finance, Google News, Google Trends, Google Docs, Google Maps, AdWords czy Google Desktop. Niemniej jednak to właśnie dzięki swojej wyszukiwarce Google stał się synonimem wyszukiwania treści w Internecie - nikt dziś nie „yahooje” i nie „binguje”; wszyscy „googlują”.

W Unii Europejskiej udziały Google na rynku wyszukiwania wynoszą ponad $90 \%{ }^{27}$. Świat szukający informacji w sieci za pomocą Google Search staje się poniekąd od niego uzależniony: tylko co sekundę w Google Search pojawia się

26 W. Oremus, Google’s Big Break, www.slate.com/articles/business (dostęp: 12.06.2016).

${ }^{27}$ Ochrona konkurencji: Komisja (...), www.europa.eu/rapid/press-release (dostęp: 18.06.2016). 
3,1 miliona zapytań ${ }^{28}$. Google jednak na tym nie poprzestaje. Opierając się na rozwijanych przez siebie rozwiązaniach z zakresu sztucznej inteligencji, proponuje coraz doskonalsze sposoby wyszukiwania treści w sieci: uwzględnia i poprawia przy tym błędy w pisowni, obsługuje zapytania głosowe, rozumie kontekst zapytania, a także jest w stanie odgadnąć, czego poszukuje użytkownik sieci, nim ten skończy wpisywać treść pytania w oknie wyszukiwania. „Gdyby wyłączono Google’a, byłaby to prawdziwa katastrofa. Żadna z pozostałych wyszukiwarek nie posiada porównywalnej infrastruktury" - uważa doktor Wolfgang Sander-Beuermann, badacz wyszukiwarek internetowych $^{29}$. Ta potężna infrastruktura firmy, która w 130 językach obsługuje globalny przesył ogromnych ilości informacji oraz przechowuje petabajty danych, świadczy dziś o przewadze firmy na rynku wyszukiwania. Trudno sobie wyobrazić, aby ktoś w tym obszarze mógł stać się dla Google zagrożeniem - nawet Microsoft traci miliardy dolarów na tym polu, próbując konkurować z firmą założoną ponad 20 lat temu przez młodych doktorantów ${ }^{30}$.

\section{Bibliografia}

Battelle J., Szukaj. Jak Google i konkurencja wywołali biznesowa i kulturowa rewolucję, Wydawnictwo Naukowe PWN, Warszawa 2006.

Brandt R.L., Potęga Google’a: poznaj sekrety Larry'ego i Sergeya, Znak, Kraków 2011.

Diamond J., Strzelby, zarazki, maszyny. Losy ludzkich społeczeństw, Prószyński i S-ka, Warszawa 2000.

Ippolita, The Dark Side of Google, Institute of Network Cultures, Amsterdam 2013.

Livingston J., Founders at Work: Stories of Startups' Early Days, Apress, New York 2008.

Mendelson B.J., Social Media to ściema, Wydawnictwo Helion, Gliwice 2014.

Reppesgaard L., Imperium Google. Google zna Cięlepiej, niż sądzisz..., BC.edu, Warszawa 2009.

Suárez Sánchez-Ocaña A., Tajemnice Google’a. Wielki Brat ery informatycznej, Bellona, Warszawa 2013.

\section{Źródła internetowe:}

Allen R., What happens online in 60 seconds?, www.smartinsights.com/internet-marketing-statistics/happens-online-60-seconds.

Alta Vista, www.web.archive.org/web/19961022174810/http://www.altavista.com.

Ochrona konkurencji: Komisja kieruje do Google pisemne zgłoszenie zastrzeżeń w zwiazku z systemem operacyjnym Android $i$ aplikacjami mobilnymi, www.europa.eu/rapid/press-release_IP-16-1492_pl.htm.

Oremus W., Google's Big Break, www.slate.com/articles/business/when_big_businesses_were_ small/2013/10/google_s_big_break_how_bill_gross_goto_com_inspired_the_adwords_ business.

Sherman Ch., Search Engine Birthdays, www.searchenginewatch.com/sew/news/2064538/ search-engine-birthdays.

${ }^{28}$ R. Allen, What happens online in 60 seconds?, www.smartinsights.com (dostęp: 12.05.2016).

${ }^{29}$ L. Reppesgaard, dz. cyt., s. 17.

30 B.J. Mendelson, Social Media to ściema, Wydawnictwo Helion, Gliwice 2014, s. 33. 